\title{
Pediatric adverse tracheal intubation associated events following noninvasive ventilation failure
}

\author{
Christina Walsh $^{1 *}$, Josep Panisello" ${ }^{1}$ Joana Tala $^{1}$, Akira Nishisaki², Guillaume Emeriaud ${ }^{3}$ and John S. Giuliano Jr. ${ }^{1}$ \\ ${ }^{1}$ Division of Pediatric Critical Care, Yale University School of Medicine, New Haven, CT, USA \\ ${ }^{2}$ Department of Anesthesiology and Critical Care Medicine, The Children's Hospital of Philadelphia, Philadelphia, PA, USA \\ ${ }^{3}$ Pediatric Intensive Care Unit, CHU Sainte-Justine, Université de Montréal, Montréal, Québec, Canada
}

\begin{abstract}
Objective: To determine if children intubated after failed Noninvasive Ventilation (NIV) have a higher occurrence of Tracheal Intubation Associated Events (TIAEs) compared to those intubated immediately.

Methods: We conducted a retrospective study of all Tracheal Intubations (TIs) in a tertiary pediatric intensive care unit from $1 / 2013$ to $12 / 2015$. Data were collected from National Airway Registry for Kids, Virtual PICU System, and chart review. We excluded TI in children on chronic NIV, endotracheal tube exchange, nonemergent TI for procedures, and cases with insufficient documentation. We defined NIV as continuous or bilevel pressure $\geq 5 \mathrm{~cm} \mathrm{H}_{2} \mathrm{O}$ or high flow nasal cannula $\geq 4 \mathrm{~L} / \mathrm{min}$ for infants and $\geq 5 \mathrm{~L} / \mathrm{min}$ for children. NIV failure was defined as TI after $>1 \mathrm{~h}$ of exposure to NIV; it was further characterized as acute (1-4h) or delayed ( $>4 \mathrm{~h}$ ). Our primary outcome was occurrence of severe TIAEs and/or desaturation $\left(\mathrm{SpO}_{2}\right.$ drop $\left.>20 \%\right)$. Data were analyzed using Fisher's Exact Test, Chi Square, Mann-Whitney UTest, and logistic regression.

Results: One-hundred-forty-four of 192 intubations (75\%) were included, of which 48 (33\%) were primary TIs and 96 (67\%) were after NIV failure. The median duration of NIV prior to failure was $14 \mathrm{~h}$ (IQR 5, 45). TIAEs/desaturation occurred in $33 \%$ of intubations and were not different between the two groups after adjusting for potential confounders ( $25 \%$ vs. 38\%; $\mathrm{p}=0.134$, aOR 2.15, 95\% CI 0.77-6.03). Additionally, there was no difference between occurrence of severe TIAEs/ desaturation in acute compared to delayed NIV failure (26\% vs. $19 \% ; \mathrm{p}=0.558)$.
\end{abstract}

Conclusion: TI after NIV failure is common. However, there was no difference in the occurrence of severe TIAEs/desaturation in primary TI versus TI after NIV failure, suggesting NIV failure does not increase the risk of TIAEs.

\section{Introduction}

Tracheal Intubation (TI) can be a life-saving intervention in critically ill pediatric patients, but it carries a high risk that can be associated with life-threatening complications. In recent studies of Pediatric Intensive Care Unit (PICU) intubations, significant desaturation occurred in 15$48 \%$ of intubations, adverse TI associated events (TIAEs) in $18-41 \%$, and severe TIAEs in 3-7\% [1-11]. Patient, provider, and intubation characteristics can be associated with increased occurrence of TIAEs and significant desaturation [1-9,12]. Identified risk factors include history of difficult airway, anatomic signs of difficult airway, patient weight, comorbidities, unstable hemodynamics, number of intubation attempts, timing of intubation, and training level of the intubating laryngoscopist $[1,3-9,12,13]$.

Noninvasive Mechanical Ventilation (NIV), including High Flow Nasal Cannula Oxygen (HFNC), is a commonly used mode of support for children with acute respiratory failure. While HFNC is not always considered NIV, multiple studies in infants, children, and adults have shown that it can generate clinically significant proximal airway distending pressures [14-18]. NIV can effectively treat acute respiratory failure in many children who otherwise would have required TI for respiratory support [18-31]. NIV has been shown to decrease intubation rates in certain groups of children as well as to decrease total ventilator time, length of stay, and overall treatment cost $[23,24,26,29,30,31]$. However, $8-43 \%$ of children treated with NIV for acute respiratory failure eventually will fail and require intubation [18-32]. Risk factors for NIV failure include patient age, comorbid condition, pneumonia or other infection, and higher risk of mortality and organ dysfunction scores [19,22,26-28,30]. Although there are no clear algorithms for predicting which children will fail NIV and require TI, NIV responders typically show improvement in vital sign and blood gas parameters within $2-4$ hours of initiating therapy $[19,21,22$, $26,28,30,31,33]$.

A recent single-center study suggested that TI after NIV failure may be associated with higher risk of TIAEs and desaturation, although the findings did not reach statistical significance [30]. Given the overlap in both suspected and documented risk factors for both TIAEs and NIV failure, we aim to further investigate the association between NIV failure and TIAEs. The objective of this study is to compare the occurrence of TIAEs and significant desaturation in children primarily intubated to those intubated after NIV failure in order to better understand

Correspondence to: Christina Walsh, MD, Yale University, 333 Cedar St, PO Box 208064, New Haven, CT 06520-8064, Tel: 203-785-4651; E-mail: Christina.walsh@yale.edu

Key words: NEAR4KIDS, Safety, PICU, HFNC, CPAP, BiPAP

Received: September 03, 2016; Accepted: September 27, 2016; Published: September 30, 2016 
the potential safety risks of TI after NIV failure. We hypothesize that children requiring TI after NIV failure will have a higher occurrence of TIAEs and desaturation due to prolonged respiratory failure with vital sign instability and decreased functional residual capacity compared to children primarily intubated.

\section{Methods}

We conducted a single-center, retrospective review of prospectively collected data from the National Emergency Airway Registry for Children (NEAR4KIDS) network [7,34]. We reviewed all TIs occurring in the Yale-New Haven Hospital PICU over a three-year period from January 1, 2013 to December 31, 2015. Our PICU is a 19-bed mixed cardiac/medical/surgical unit in a tertiary care teaching center. The Yale University Internal Review Board approved the study and granted a waiver for parental consent. We excluded TI in children on chronic NIV therapy, endotracheal tube exchange, non-emergent TI for a procedure, and cases with insufficient documentation.

We defined "primary tracheal intubation" as TI occurring after no exposure to NIV or only transient exposure lasting less than one hour during transport or in preparation for intubation. We defined "NIV failure" as TI occurring after more than 1 hour of support with any combination of Nasal Intermittent Positive Pressure Ventilation (NIPPV) or bi-level Positive Airway Pressure (BiPAP) at any pressure, Continuous Positive Airway Pressure (CPAP) greater than $5 \mathrm{cmH}_{2} \mathrm{O}$, or heated humidified High Flow Nasal Cannula (HFNC) with a minimum flow rate of $4 \mathrm{~L} / \mathrm{min}$ in infants less than one year of age and $5 \mathrm{~L} / \mathrm{min}$ in children greater than or equal to one year of age. Within the NIV failure group, we defined acute failure as 1-4 hours and delayed failure as greater than 4 hours based on physiologic response patterns shown in the literature $[19,21,22,26,28,30,31]$.

Data were collected from review of our internal site NEAR4KIDS database, Virtual PICU System, and individual patient chart reviews. Patient data included gender, age, weight, presence of a comorbidity (prematurity $<37$ weeks gestational age, chronic pulmonary disease requiring care by a pulmonologist, repaired or unrepaired congenital heart disease, neuromuscular disease, or oncologic diagnosis), primary diagnosis, Pediatric Risk of Mortality III (PRISM3) score at PICU admission, tachycardia or tachypnea in the hour prior to intubation (using age-specific ranges), lowest peripheral oxygen saturation $\left(\mathrm{SpO}_{2}\right)$ in the hour prior to intubation, indication for intubation (respiratory failure, unstable hemodynamics, neurologic impairment), concern for difficult airway (documented history of difficult airway or abnormal clinical airway assessment), and duration of NIV. Intubation characteristics included laryngoscopist training level for the first TI attempt, TI method, and number of TI attempts [35-37].

The primary outcome was occurrence of any severe TIAEs and/ or significant desaturation (TIAEs/desaturation). TIAEs were defined a priori by the NEAR4KIDS collaborative. Severe TIAEs are cardiac arrest, esophageal intubation with delayed recognition, emesis with aspiration, hypotension requiring intervention (fluid and/or pressors), laryngospasm, malignant hyperthermia, pneumothorax or pneumomediastinum, and direct airway injury [7]. Significant desaturation was defined as pulse oximetry $<80 \%$ saturation with an initial saturation $>94 \%$ or change of more than $20 \%$ from initial saturation. Secondary outcomes included duration of intubation reported as ventilator-free days ( 28 days), ICU length of stay, and hospital length of stay.

Sample size calculation using previously published rates of severe
TIAEs and desaturations from Crulli et al. and our own preliminary data from 2013 estimated a necessary sample size of 148 (74 per group) for a two-sided alpha of 0.05 and $80 \%$ power. Statistical analysis was done using SPSS 21.0 (IBM SPSS Statistics for Windows, Version 1.0. Armonk, NY. IBM Corp). Categorical variables are presented as percentages and analyzed using Fisher's Exact Test or Chi-Square as appropriate. Continuous variables are presented as median with interquartile range and analyzed using Mann-Whitney $U$ Test. A p-value of $\leq 0.05$ was statistically significant.

We used both bivariate and multivariable regression analysis to identify and account for potential confounders affecting the association between TIAEs/desaturation and NIV exposure. Bivariate regression included all variables known to be associated with TIAEs in the literature and variables unevenly distributed between the control and exposure groups: PRISM3 score, number of intubation attempts, indication for intubation, training level of laryngoscopist, weight, and concern for difficult airway. Bivariate analysis was considered significant for inclusion in the multivariable regression model if the $\mathrm{p}$ value was less than 0.2 in its association with both NIV exposure and TIAEs/desaturation. We also performed a secondary analysis of the NIV failure group to assess for an association between duration of NIV and occurrence of TIAEs using NIV duration as a continuous variable and classifying NIV failure as acute (1-4 hours) or delayed ( $>4$ hours).

\section{Results}

Over the three-year study period, 192 TIs were reviewed. Fortyeight (25\%) were excluded due to predefined exclusion criteria (Figure $1)$. Of the remaining 144 intubations, $48(33 \%)$ were primary TIs and $96(67 \%)$ were TI following NIV failure. Within the NIV failure group, NIV was given with HFNC alone in 19\%, CPAP alone in $13 \%$, BiPAP alone in $22 \%$, and multiple modes in $46 \%$. In patients supported with multiple modes, HFNC was typically the first mode used before progressing to $\mathrm{CPAP}$ or BiPAP.

Table 1 describes patient characteristics for each group. Gender, age, weight, PRISM3 scores, pre-intubation tachypnea and tachycardia, preintubation lowest $\mathrm{SpO}_{2}$, presence of comorbidities, and pre-intubation concern for difficult airway were not significantly different between the two groups. The reason for intubation differed significantly between the two groups with respiratory failure being less common in the primary TI group ( $38 \%$ vs. $80 \%$; $<<0.001)$ and neurologic impairment being more common in the primary TI group ( $48 \%$ vs. $14 \%$; $\mathrm{p}<0.001)$.

Intubation characteristics were similar between the two groups.

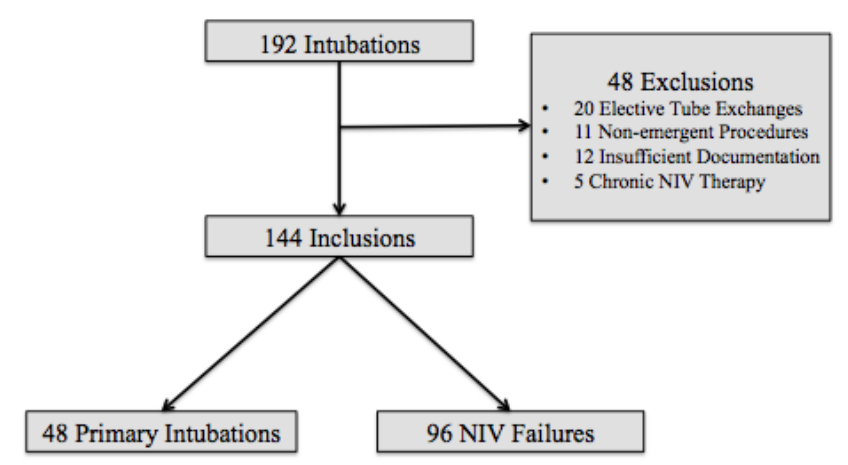

Figure 1. Tracheal Intubation Flow Diagram . 
Table 1. Characteristics of patients with Primary TI and TI following NIV failure

\begin{tabular}{|c|l|l|l|}
\hline Characteristics & Primary TI (n=48) & NIV Failure (n=96) & p-value \\
\hline Gender (female) & $16(33 \%)$ & $37(39 \%)$ & 0.541 \\
\hline Age (months) & $21(3,92)$ & $7(2,46)$ & 0.133 \\
\hline Weight $(\mathrm{kg})$ & $12(6,24)$ & $7(5,18)$ & 0.096 \\
\hline PRISM3 & $10(3,16)$ & $5(3,13)$ & 0.074 \\
\hline Tachycardia & $23(48 \%)$ & $59(62 \%)$ & 0.122 \\
\hline Tachypnea & $23(48 \%)$ & $37(39 \%)$ & 0.282 \\
\hline $\mathrm{SpO}_{2}$ & $96(85,99)$ & $94(84,100)$ & 0.911 \\
\hline Comorbidities & $27(56 \%)$ & $65(68 \%)$ & 0.177 \\
\hline Difficult Airway & $11(23 \%)$ & $28(29 \%)$ & 0.426 \\
\hline Reason for Intubation & & & \\
\hline Respiratory Failure & $18(38 \%)$ & $77(80 \%)$ & $<0.001$ \\
\hline Unstable Hemodynamics & $7(15 \%)$ & $6(6 \%)$ & 0.125 \\
\hline Neurologic Impairment & $23(48 \%)$ & $13(14 \%)$ & $<0.001$ \\
\hline
\end{tabular}

NIV: Non-invasive ventilation; TI: Tracheal Intubation; kg: kilogram; PRISM: Pediatric Risk of Mortality; $\mathrm{SpO}_{2}$ : peripheral oxygen saturation.

Data are reported as number (percentage) or median (interquartile range) with p-value from Chi Square, Fisher's Exact Test (*), or Mann-Whitney U as appropriate. Tachypnea and tachycardia refer to the hour prior to intubation using age-based normal values. Difficult airway refers to pre-intubation concern for difficult airway based on patient exam or history.

Table 2. Outcome Measures in Primary TI compared to TI after NIV failure.

\begin{tabular}{|l|c|c|c|}
\hline & $\begin{array}{c}\text { Primary TI } \\
(\mathbf{n = 4 8})\end{array}$ & $\begin{array}{c}\text { NIV Failure } \\
(\mathbf{n = 9 6})\end{array}$ & p-value \\
\hline TIAE/Desaturation & $12(25 \%)$ & $36(38 \%)$ & 0.134 \\
\hline Severe TIAE & $5(10 \%)$ & $6(6 \%)$ & $0.507^{*}$ \\
\hline Desaturation & $10(21 \%)$ & $33(34 \%)$ & 0.094 \\
\hline
\end{tabular}

NIV: non-invasive ventilation; TI: Tracheal Intubation; TIAE: tracheal intubation associated event

Data are presented as numbers (\%). P-value is for Fisher's Exact Test (") or Chi Square Test.

There were no significant differences between the primary TI and NIV failure groups in training level of the laryngoscopist on first attempt ( $21 \%$ vs. $17 \%$ resident/RN, $67 \%$ vs. $72 \%$ fellow/APRN, $13 \%$ vs. $12 \%$ attending; $\mathrm{p}=0.794$ ) or number of intubation attempts (median 2 IQR 1,3 vs. median 1 IQR 1, 2; $\mathrm{p}=0.151$ ). Direct laryngoscopy was used for $96 \%$ of intubations, video laryngoscopy for $3 \%$, and tube exchange over a bougie for $1 \%$; all intubations were oral.

The primary outcome of occurrence of TIAEs/desaturation occurred in $33 \%$ of all intubations and occurred similarly in both the primary TI and NIV failure groups ( $25 \%$ vs. $38 \%$; $\mathrm{p}=0.134)$. Table 2 describes the breakdown of severe TIAE and desaturation. There were no significant differences in the individual outcomes. There were eleven severe TIAEs consisting of two cardiac arrests without mortality, two episodes of laryngospasm, six episodes of hypotension requiring fluid or pressors, and one direct airway injury. There were no significant differences in any secondary outcomes including ventilator-free days (median 18 IQR 3, $23 v s$. median 16 IQR 5, 21; p=0.317), ICU length of stay in days (median $15 \mathrm{IQR} 7,33$ vs. median $21 \mathrm{IQR} 11,41 ; \mathrm{p}=0.056$ ), or hospital length of stay in days (median 22 IQR 12, $50 \mathrm{vs}$. median 31 IQR 16, 73; $\mathrm{p}=0.052$ ).

Bivariate analysis identified weight, PRISM3 score, number of intubation attempts, respiratory indication for intubation, and neurologic indication for intubation as potential confounders. NIV exposure was not significantly associated with TIAEs/desaturation when accounting for these confounders (aOR 2.147, 95\% CI 0.765 6.026). Our analysis included 56 patients who were intubated after failed or unplanned extubation (15 primary TIs and 41 TIs following NIV failure). In repeat analysis with these patients excluded, there remained no significant association between TIAEs/desaturation and pre-intubation NIV exposure ( $36 \%$ vs. $38 \%$; $\mathrm{p}=0.865$, aOR $2.636,95 \%$ CI 0.624-11.129).

In secondary analysis of the NIV failure group, 96 patients were intubated after NIV failure with a median NIV duration of 14 hours (IQR 5, 45 hours) prior to failure. The median duration of NIV prior to failure was similar in patients who did not have TIAEs/desaturation compared to those who did (median 16 hours IQR 5, 46 vs. median 12 hours IQR 4, 45; $\mathrm{p}=0.988$ ). Within the NIV failure group, 23 patients (24\%) had acute failure with the median duration of NIV being 2 hours (IQR 2, 3 hours). Seventy-three (76\%) had delayed failure with the median duration of NIV being 27 hours (IQR 10, 60 hours). TIAEs/ desaturation occurred in $26 \%$ of acute failure intubations and $19 \%$ of delayed failure intubations $(\mathrm{p}=0.558)$.

\section{Discussion}

In this retrospective single-center study, we report that TI after NIV failure was common, occurring in $67 \%$ of TIs and that severe TIAEs/desaturation occurred in $33 \%$ of all TIs. The occurrence of TIAEs/desaturation was similar when comparing those who required primary TI to those requiring TI after failed NIV, and there was no significant association between TIAEs/desaturation and NIV exposure after adjusting for number of intubation attempts, weight, PRISM3 score, respiratory indication, and neurologic indication. Ventilatorfree days, PICU length of stay, and hospital length of stay were also similar between the two groups. We also report that within the NIV failure group, there was no significant difference in the occurrence of TIAEs/desaturation after acute failure compared to delayed failure. Collectively, these data suggest that NIV prior to TI may not be associated with increased risk for severe TIAEs/desaturation, in contrast to our hypothesis.

This study is among the few current studies to assess intubation safety after NIV failure in pediatric patients. A recent study by Crulli et al. reported severe TIAEs/desaturation in $24 \%$ of primary TIs compared to $41 \%$ of TIs after NIV failure, similar to $25 \%$ and $38 \%$ in our study, respectively. Notable differences between the two studies include our inclusion of HFNC in the definition of NIV and our exclusion of non-emergent TIs for procedures. Previous studies have shown a decreased occurrence of TIAEs with non-emergent intubations $[1,7,38]$. Although non-emergent TIs prior to a procedure are typically primary intubations our primary TI group had similar occurrence of TIAEs/desaturation as Crulli et al. HFNC is a frequently used mode of NIV and therefore important to include, but our study was not adequately powered to determine an association between mode of NIV and TIAEs/desaturation.

Similar to many recent studies, there was a significant association between increasing number of intubation attempts and increasing occurrence of TIAEs $[1,3,6,12,38-40]$. Unlike several recent studies, we did not detect a significant association between TIAEs and training levels, which may be due to local practice habits of preferentially allowing residents to intubate the most stable patients [7,9,40-42]. Neither number of attempts nor training level had significant effect on the association between TIAEs and NIV failure.

The two comparison groups differed in primary reason for intubation (respiratory, neurologic, or unstable hemodynamics). "Reason for intubation" is similar to "diagnostic category" and "shock," which have been significantly associated with TIAEs in other studies $[7,42]$. Respiratory failure was the primary indication for intubation in 
only $38 \%$ in the primary intubation group compared to $80 \%$ of children in the NIV failure group, whereas neurologic indication for intubation occurred in $48 \%$ of primary intubations and only $14 \%$ of NIV failure intubations. These findings are consistent with typical clinical practice of using NIV for treatment of respiratory illness and not for respiratory support in neurologically impaired patients who are unable to protect their airway. Despite the differences between the two groups, the regression model showed no difference in the association between TIAEs/desaturation and NIV failure when adjusted for the number of intubation attempts and neurologic indication for intubation. Since most patients at our institution are extubated to NIV, there was a potential for confounding by including the 56 patients who were unplanned or failed extubation. We repeated the analyses excluding these patients but continued to find no difference between the two groups.

The NIV failure group had lower, but not significantly different, median PRISM3 scores at PICU admission, suggesting that sicker children may have been intubated primarily and those with lower risk of mortality scores were trialed on NIV prior to intubation. PRISM3 scores have been associated with NIV failure but not with TIAEs [22,27, 30]. Sufficient data were not available via chart review to calculate pediatric organ dysfunction scores immediately prior to intubation, but in the hour prior to intubation, the two groups had similar occurrence of tachypnea and tachycardia for age and similar lowest $\mathrm{SpO}_{2}$ levels. Since PRISM3 scores are collected at PICU admission and not on day of intubation, the similar physiologic parameters in the hour before intubation suggest that the groups were similar in their degree of illness despite the difference in PRISM3 scores.

There are limitations of this study that are important to acknowledge. First, it is a retrospective study of prospectively collected data and causation cannot be inferred. Second, the NEAR4KIDS collaborative database is self-reported. There are multiple safeguards and quality measures in place to optimize data collection but the possibility of TIAE and desaturation reporting bias still remains. Third, it is unclear how much distending pressure certain levels of HFNC provide. The minimum flow limits chosen were levels that most institutions in the NEAR4KIDS collaborative agree to be NIV rather than simple oxygen delivery. However, the liter flows chosen cannot adequately account for all determinants of distending pressure delivered by HFNC such as cannula size, seal, presence of nasal secretions, agitation, and open mouth, among others. Finally, we present data on a limited sample size over the designated three-year time period. Although we detected no difference between the primary intubation and NIV failure groups or between the acute and delayed failure groups, our study was slightly underpowered and a larger sample size would have given the findings higher power and less risk of Type II error, especially for the secondary analysis. Given these limitations, our data may not be generalizable to all PICUs.

\section{Conclusions}

There have been ongoing attempts to identify risk factors for adverse intubation events with the goal of modifying these risk factors and improving patient safety. Our study did not detect a difference in the occurrence of severe TIAEs/desaturation in children being intubated after a failed trial of NIV compared to those being intubated primarily. Our data suggest that trialing a patient on NIV in an attempt to prevent intubation may be safe without increasing the risk of severe TIAEs or significant desaturation in children who ultimately fail NIV, but further work in a larger, multi-center study is warranted.

\section{Acknowledgements}

The authors acknowledge the Yale University Pediatric Critical Care fellows, respiratory therapists, and nurses for their participation in self-reporting intubation outcomes and their commitment to improving intubation safety.

\section{Past presentation of results}

Platform presentation at Eastern Society for Pediatric Research (March 2016, Philadelphia, PA) and poster presentation at Pediatric Academic Society (May 2016, Baltimore, MD).

\section{References}

1. Carroll CL, Spinella PC, Corsi JM, Stoltz P, Zucker AR (2010) Emergent endotracheal intubations in children: be careful if it's late when you intubate. Pediatr Crit Care Med 11: 343-348. [Crossref]

2. Crulli B, Loron G, Nishisaki A, Harrington K, Essouri S, et al. (2016) Safety of paediatric tracheal intubation after non-invasive ventilation failure. Pediatr pulmonol 51: 165-172. [Crossref]

3. Lee JH, Turner DA, Kamat P, Nett S, Shults J, et al. (2016) Pediatric Acute Lung I, Sepsis I, National Emergency Airway Registry for C: The number of tracheal intubation attempts matters! A prospective multi-institutional pediatric observational study. $B M C$ pediatrics 16: 58 .

4. Nett S, Emeriaud G, Jarvis JD, Montgomery V, Nadkarni VM, et al. (2014) Site-level variance for adverse tracheal intubation-associated events across 15 North American PICUs: a report from the national emergency airway registry for children*. Pediatr Crit Care Med 15: 306-313. [Crossref]

5. Nishisaki A, Donoghue AJ, Colborn S, Watson C, Meyer A, et al. (2010) Effect of just-in-time simulation training on tracheal intubation procedure safety in the pediatric intensive care unit. Anesthesiology 113: 214-223. [Crossref]

6. Nishisaki A, Ferry S, Colborn S, DeFalco C, Dominguez T, et al. (2012) Characterization of tracheal intubation process of care and safety outcomes in a tertiary pediatric intensive care unit. Pediatr Crit Care Med 13: e5-e10. [Crossref]

7. Nishisaki A, Turner DA, Brown CA 3rd, Walls RM, Nadkarni VM, et al. (2013) A National Emergency Airway Registry for children: landscape of tracheal intubation in 15 PICUs. Critical Care Medicine 41: 874-885. [Crossref]

8. Rehder KJ, Giuliano JS Jr., Napolitano N, Turner DA, Nuthall G, et al. (2015) Increased Occurrence of Tracheal Intubation-Associated Events During Nights and Weekends in the PICU. Crit Care Med 43: 2668-2674. [Crossref]

9. Sanders RC Jr., Giuliano JS Jr., Sullivan JE, Brown CA 3rd, Walls RM, et al. (2013) Level of trainee and tracheal intubation outcomes. Pediatrics 131: e821-828. [Crossref]

10. Sanders RC Jr, Nett ST, Davis KF, Parker MM, Bysani GK, et al. (2016) Family Presence During Pediatric Tracheal Intubations. JAMA Pediatr 170: e154627. [Crossref]

11. Tarquinio KM, Howell JD, Montgomery V, Turner DA, Hsing DD, et al. (2015) Current medication practice and tracheal intubation safety outcomes from a prospective multicenter observational cohort study. Pediatr Crit Care Med 16: 210-218. [Crossref]

12. Graciano AL, Tamburro R, Thompson AE, Fiadjoe J, Nadkarni VM, et al. (2014) Incidence and associated factors of difficult tracheal intubations in pediatric ICUs: a report from National Emergency Airway Registry for Children: NEAR4KIDS Intensive Care Med 40: 1659-1669. [Crossref]

13. Fiadjoe JE, Nishisaki A, Jagannathan N, Hunyady AI, Greenberg RS, et al. (2016) Airway management complications in children with difficult tracheal intubation from the Pediatric Difficult Intubation (PeDI) registry: a prospective cohort analysis. Lancet Respir Med 4: 37-48. [Crossref]

14. Arora B, Mahajan P, Zidan MA, Sethuraman U (2012) Nasopharyngeal airway pressures in bronchiolitis patients treated with high-flow nasal cannula oxygen therapy. Pediatr Emerg Care 28: 1179-1184. [Crossref]

15. Hasan RA, Habib RH (2011) Effects of flow rate and airleak at the nares and mouth opening on positive distending pressure delivery using commercially available highflow nasal cannula systems: a lung model study. Pediatr Crit Care Med 1200: e29-e33. [Crossref]

16. Milési C1, Baleine J, Matecki S, Durand S, Combes C, et al (2013) Is treatment with a high flow nasal cannula effective in acute viral bronchiolitis? A physiologic study Intensive Care Med 39: 1088-1094. [Crossref] 
17. Parke R, McGuinness S, Eccleston M (2009) Nasal high-flow therapy delivers low level positive airway pressure. Br J Anaesth 103: 886-890. [Crossref]

18. Spentzas T, Minarik M, Patters AB, Vinson B, Stidham G (2009) Children with respiratory distress treated with high-flow nasal cannula. J Intensive Care Med 24: 323328. [Crossref]

19. Abadesso C, Nunes P, Silvestre C, Matias E, Loureiro H, et al. (2012) Non-invasive ventilation in acute respiratory failure in children. Pediatr Rep 4: e16. [Crossref]

20. Bernet V, Hug MI, Frey B (2005) Predictive factors for the success of noninvasive mask ventilation in infants and children with acute respiratory failure Pediatr Crit Care Med 6: 660-664. [Crossref]

21. Dohna-Schwake C, Stehling F, Tschiedel E, Wallot M, Mellies U (2011) Non-invasive ventilation on a pediatric intensive care unit: feasibility, efficacy, and predictors of success. Pediatr Pulmonol 46: 1114-1120. [Crossref]

22. Essouri S, Chevret L, Durand P, Haas V, Fauroux B, et al. (2006) Noninvasive positive pressure ventilation: five years of experience in a pediatric intensive care unit. Pediatr Crit Care Med 7: 329-334. [Crossref]

23. Essouri S, Laurent M, Chevret L, Durand P, Ecochard E, et al. (2014) Improved clinical and economic outcomes in severe bronchiolitis with pre-emptive nCPAP ventilatory strategy. Intensive Care Med 40: 84-91. [Crossref]

24. Ganu SS, Gautam A, Wilkins B, Egan J (2012) Increase in use of non-invasive ventilation for infants with severe bronchiolitis is associated with decline in intubation rates over a decade. Intensive Care Med 38: 1177-1183. [Crossref]

25. Gupta P, Kuperstock JE, Hashmi S, Arnolde V, Gossett JM, et al. (2013) Efficacy and predictors of success of noninvasive ventilation for prevention of extubation failure in critically ill children with heart disease. Pediatr cardiol 34: 964-977. [Crossref]

26. Lazner MR, Basu AP, Klonin H (2012) Non-invasive ventilation for severe bronchiolitis: analysis and evidence. Pediatr Pulmonol 47: 909-916. [Crossref]

27. Mayordomo-Colunga J, Medina A, Rey C, Diaz JJ, Concha A, et al. (2009) Predictive factors of non invasive ventilation failure in critically ill children: a prospective epidemiological study. Intensive Care Med 35: 527-536. [Crossref]

28. Munoz-Bonet JI, Flor-Macian EM, Brines J, Rosello-Millet PM, Cruz Llopis M, et al. (2010) Predictive factors for the outcome of noninvasive ventilation in pediatric acute respiratory failure. Pediatr Crit Care Med 11: 675-680. [Crossref]

29. Wing R, James C, Maranda LS, Armsby CC (2012) Use of high-flow nasal cannula support in the emergency department reduces the need for intubation in pediatric acute respiratory insufficiency. Pediatr Emerg Care 28: 1117-1123. [Crossref]

30. Yaman A, Kendirli T, Odek C, Otes C, Tasyapar N, et al. (2016) Efficacy of noninvasive mechanical ventilation in prevention of intubation and reintubation in the pediatric intensive care unit. J Crit Care 32: 175-181. [Crossref]

31. Yanez LJ, Yunge M, Emilfork M, Lapadula M, Alcantara A, et al. (2008) A prospective, randomized, controlled trial of noninvasive ventilation in pediatric acute respiratory failure. Pediatr Crit Care Med 9: 484-489. [Crossref]

32. James CS, Hallewell CP, James DP, Wade A, Mok QQ (2011) Predicting the success of non-invasive ventilation in preventing intubation and re-intubation in the paediatric intensive care unit. Intensive Care Med 37: 1994-2001. [Crossref]

33. Bressan S, Balzani M, Krauss B, Pettenazzo A, Zanconato S, et al. (2013) High-flow nasal cannula oxygen for bronchiolitis in a pediatric ward: a pilot study. Eur J Pediat 172: 1649-1656. [Crossref]

34. Li S, Rehder KJ, Giuliano JS Jr., Apkon M, Kamat P, et al. (2016) Development of a Quality Improvement Bundle to Reduce Tracheal Intubation-Associated Events in Pediatric ICUs. Am J Med Qual 31: 47-55. [Crossref]

35. Pollack MM, Patel KM, Ruttimann UE (1996) PRISM III: an updated Pediatric Risk of Mortality score. Crit Care Med 24: 743-752. [Crossref]

36. Pichard CP, Robinson RE, Skolasky RL, Fedarko NS, Leet AI (2009) Surgical blood loss during femoral rodding in children with osteogenesis imperfecta. J Child Orthop 3: 301-305. [Crossref]

37. Chameides L: Pediatric Advanced Life Support: American Heart Association; 2011.

38. Hatch LD, Grubb PH, Lea AS, Walsh WF, Markham MH, et al. (2016) Endotracheal Intubation in Neonates: A Prospective Study of Adverse Safety Events in 162 Infants. J Pediatr 168: 62-66. [Crossref]

39. Hasegawa K, Shigemitsu K, Hagiwara Y, Chiba T, Watase H, et al. (2012) Association between repeated intubation attempts and adverse events in emergency departments: an analysis of a multicenter prospective observational study. Ann Emerg Med 60: 749754. [Crossref]

40. Griesdale DE, Bosma TL, Kurth T, Isac G, Chittock DR (2008) Complications of endotracheal intubation in the critically ill. Intensive Care Med 34: 1835-1842. [Crossref]

41. Foglia EE, Ades A, Napolitano N, Leffelman J, Nadkarni V, et al. (2015) Factors Associated with Adverse Events during Tracheal Intubation in the NICU. Neonatology 108: 23-29. [Crossref]

42. Jaber S, Amraoui J, Lefrant JY, Arich C, Cohendy R, et al. (2006) Clinical practice and risk factors for immediate complications of endotracheal intubation in the intensive care unit: a prospective, multiple-center study. Crit Care Med 34: 2355-2361. [Crossref]

Copyright: (C2016 Walsh C. This is an open-access article distributed under the terms of the Creative Commons Attribution License, which permits unrestricted use, distribution, and reproduction in any medium, provided the original author and source are credited. 